\title{
Targeting cyclin B I inhibits proliferation and sensitizes breast cancer cells to taxol
}

\author{
Ilija Androic ${ }^{\dagger 2}$, Andrea Krämer ${ }^{\dagger 1}$, Ruilan Yan², Franz Rödel ${ }^{4}$, Regine Gätje ${ }^{1}$, \\ Manfred Kaufmann ${ }^{1}$, Klaus Strebhardt ${ }^{\dagger 1}$ and Juping Yuan*†1
}

Address: ${ }^{1}$ Department of Obstetrics and Gynecology, School of Medicine, J.W. Goethe-University, Theodor-Stern-Kai 7, 60590 Frankfurt, Germany, ${ }^{2}$ Municipal clinics Frankfurt am Main - Hoechst, Gotenstraße 6-8, 65929 Frankfurt, Germany, ${ }^{3}$ Department of Medical Microbiology, Immunology and Cell Biology, Cancer Institute, Southern Illinois University, School of Medicine, 911N Rutledge St, Springfield, IL 62702, USA and ${ }^{4}$ Department of Radiotherapy and Oncology, School of Medicine, J.W. Goethe-University, Theodor-Stern-Kai 7, 60590 Frankfurt, Germany

Email: Ilija Androic - ilija-a@gmx.de; Andrea Krämer - abkraemer@gmx.de; Ruilan Yan - yanrl@hotmail.com;

Franz Rödel - Franz.Roedel@kgu.de; Regine Gätje - Gaetje@em.uni-frankfurt.de; Manfred Kaufmann - m.kaufmann@em.uni-frankfurt.de;

Klaus Strebhardt - strebhardt@em.uni-frankfurt.de; Juping Yuan* - yuan@em.uni-frankfurt.de

* Corresponding author †Equal contributors

Published: 29 December 2008

BMC Cancer 2008, 8:39| doi:|0.|| |86/|47|-2407-8-39|
Received: 15 April 2008

Accepted: 29 December 2008

This article is available from: http://www.biomedcentral.com/|47|-2407/8/39|

(C) 2008 Androic et al; licensee BioMed Central Ltd.

This is an Open Access article distributed under the terms of the Creative Commons Attribution License (http://creativecommons.org/licenses/by/2.0), which permits unrestricted use, distribution, and reproduction in any medium, provided the original work is properly cited.

\begin{abstract}
Background: Cyclin $\mathrm{BI}$, the regulatory subunit of cyclin-dependent kinase I (CdkI), is essential for the transition from $\mathrm{G} 2$ phase to mitosis. Cyclin $\mathrm{Bl}$ is very often found to be overexpressed in primary breast and cervical cancer cells as well as in cancer cell lines. Its expression is correlated with the malignancy of gynecological cancers.
\end{abstract}

Methods: In order to explore cyclin BI as a potential target for gynecological cancer therapy, we studied the effect of small interfering RNA (siRNA) on different gynecological cancer cell lines by monitoring their proliferation rate, cell cycle profile, protein expression and activity, apoptosis induction and colony formation. Tumor formation in vivo was examined using mouse xenograft models.

Results: Downregulation of cyclin $\mathrm{BI}$ inhibited proliferation of several breast and cervical cancer cell lines including MCF-7, BT-474, SK-BR-3, MDA-MB-23I and HeLa. After combining cyclin BI siRNA with taxol, we observed an increased apoptotic rate accompanied by an enhanced antiproliferative effect in breast cancer cells. Furthermore, control HeLa cells were progressively growing, whereas the tumor growth of HeLa cells pre-treated with cyclin BI siRNA was strongly inhibited in nude mice, indicating that cyclin $\mathrm{BI}$ is indispensable for tumor growth in vivo.

Conclusion: Our data support the notion of cyclin BI being essential for survival and proliferation of gynecological cancer cells. Concordantly, knockdown of cyclin BI inhibits proliferation in vitro as well as in vivo. Moreover, targeting cyclin BI sensitizes breast cancer cells to taxol, suggesting that specific cyclin BI targeting is an attractive strategy for the combination with conventionally used agents in gynecological cancer therapy. 


\section{Background}

Breast and cervical cancers are the most frequent malignancies in women worldwide $[1,2]$. Uncontrolled cell proliferation, which is associated with the loss of the proper cell cycle control, is a prominent feature in these cancers. The cell cycle is controlled by a highly conserved family of cyclin-dependent kinases (Cdks) and their regulatory subunits cyclins. Among the cyclins, cyclin B1 plays a pivotal role as a regulatory subunit for Cdk1, which is indispensable for the transition from G2 phase to mitosis. Overexpression of cyclin B1 has been reported in various human tumors, such as breast cancer, cervical cancer, gastric cancer, colorectal cancer, head and neck squamous cell carcinoma and non-small-cell lung cancer [3-9] and its upregulation is closely associated with poor prognosis in various types of cancers including breast cancer $[6,10,11]$. Moreover, overexpression of cyclin B1 is involved in the resistance to radiotherapy in head and neck squamous cell carcinoma [8] and nuclear cyclin B1positive breast carcinomas are resistant to adjuvant therapy [11]. More recently, it is reported that both antibodies and $T$ cells are generated in response to aberrant cyclin B1 expression in tumors like breast cancer $[12,13]$, indicating that overexpressed cyclin B1 could serve as one of the signals to initiate the communication between cancer cells and their microenvironment.

The mechanisms accounting for overexpressed cyclin B1 are not yet totally understood. It has been reported that the tumor suppressors p53 and BRCA1 negatively regulate the promoter of cyclin B1 [14-17], whereas the oncogene c-Myc positively regulates the expression of cyclin B1 in cooperation with the loss of p53 [18]. The promoter of cyclin B1 is also upregulated by 17beta-estradiol (E2), insulin-like growth factor I (IGF-I) and prolactin-releasing hormone (PRL), which are considered as the factors contributing to mammary cancer development and progression [19-21]. Moreover, cyclin B1 mRNA is significantly stabilized in cervical cancer cells infected with human papillomavirus type 18 (HPV 18) through upregulating HuR [22], a ubiquitously expressed member of the $\mathrm{Hu}$ family of RNA-binding proteins.

The highly expressed cyclin B1, even in G1 phase, binds to its partner Cdk1, which phosphorylates a series of substrates regardless of the cell cycle phase and contributes to the aggressive proliferation in neoplastic tissues [23]. In addition, overexpression of cyclin B1 is related to aneuploidy and high proliferation of human mammary carcinomas [24]. This is consistent with the observation of cyclin B1 overexpression enabling cells to override the G2 DNA damage checkpoint $[16,25,26]$. Nuclear cyclin B1, together with $\mathrm{Cdk} 1 \mathrm{AF}$, a Cdk1 mutant that cannot be phosphorylated at its inhibitory sites, induced a striking premature mitotic phenotype even after DNA damage $[25,26]$, resulting in accumulation of genomic defects, one hallmark of neoplastic development. More strikingly, enforced expression of cyclin B1 induces tetraploidy, either after mitotic spindle inhibition of nocodazole or in the absence of such inhibition if cyclin B1 is coexpressed with c-Myc [18].

Taken together, deregulation of cyclin B1 is involved in neoplastic transformation and promotes proliferation of tumor cells. Conversely, downregulation of cyclin B1, consequently reducing the activity of Cdk1/cyclin B1, could block the aggressive proliferation of tumor cells. Indeed, our previous data confirm that interfering with cyclin B1 function inhibits proliferation of human tumor cells $[27,28]$. In the present study, we focus on gynecological cancer cell lines and investigate the effect of small interfering RNA (siRNA) induced cyclin B1 knockdown on tumor cell proliferation. Interestingly, the combination of cyclin B1 siRNA with taxol substantially enhanced the inhibitory effect on proliferation of breast cancer cells. Furthermore, while control HeLa cells were progressively growing, the tumor growth of HeLa cells treated with cyclin B1 siRNA prior to inoculation was strongly inhibited in nude mice, indicating cyclin B1 is indispensable for tumor growth in vivo.

\section{Methods \\ Cell culture, reagents and cell synchronization}

Cervical cancer cell line HeLa and breast cancer cell lines MCF-7, BT-474, SK-BR-3 and MDA-MB-231 were obtained from DSMZ (Braunschweig). Fetal calf serum (FCS) was purchased from PAA laboratories (Cölbe). Opti-MEM I, oligofectamine, glutamine, penicillin, streptomycin and trypsin were obtained from Invitrogen (Karlsruhe). Taxol was from Mayne Pharma (Haar). Cells were synchronized to G1/S boundary by a double-thymidine block. Briefly, cells were treated with $2 \mathrm{mM}$ thymidine (Sigma-Aldrich, Taufkirchen) for $16 \mathrm{~h}$, released into fresh medium for $8 \mathrm{~h}$ and subjected again to thymidine for further $16 \mathrm{~h}$. To obtain prometaphase arrest, after initial thymidine incubation and $8 \mathrm{~h}$ release cells were exposed to $50 \mathrm{ng} / \mathrm{ml}$ nocodazole (Sigma-Aldrich) for $14 \mathrm{~h}$.

\section{Transfection of siRNA and the combined treatment with drugs or irradiation}

Four siRNAs targeting cyclin B1 (NCBI accession number of cyclin B1: NM 031966) were synthesized by Dharmacon Research, Inc. (Lafayette), referred to as siRNA1-4. siRNA1 against cyclin B1 corresponds to positions 340360 of the cyclin B1 open reading frame, siRNA2 to positions 476-496, siRNA3 to positions 776-796 and siRNA4 to positions 1302-1322. Control siRNA targeting green fluorescent protein (siGFP) was also purchased from Dharmacon. All siRNAs were 21 nucleotides in length and contained symmetric 3 ' overhangs of two deoxythymidines. 
Cells were transfected with siRNA using transfection reagent oligofectamine, according to the manufacturer's instructions (Invitrogen). In brief, one day prior to transfection, cells were seeded without antibiotics to a density of $50-60 \%$. In all experiments cells were transfected with siRNA1-4 or siGFP at a concentration of $10 \mathrm{nM}$. Cells were harvested $48 \mathrm{~h}$ after siRNA-treatment for cell cycle evaluation, Western blot analysis and kinase assay. The time kinetics of protein expression were carried out at $24 \mathrm{~h}, 48$ $\mathrm{h}, 72 \mathrm{~h}$ and $96 \mathrm{~h}$ and proliferation assays were performed at $24 \mathrm{~h}, 48 \mathrm{~h}$ and $72 \mathrm{~h}$ after siRNA transfection in MCF-7 cells.

For chemotherapeutic treatment, MCF-7 cells were at first transfected with siRNA and $4 \mathrm{~h}$ later followed by treatment of taxol $(3 \mathrm{ng} / \mathrm{ml})$. For irradiation, $6 \mathrm{~h}$ post transfection cells were exposed to a single dose of $8 \mathrm{~Gy}$ at room temperature by a linear accelerator (SL 75/5, Elekta, Crawley, UK) with $6 \mathrm{MEV}$ photons $/ 100 \mathrm{~cm}$ focus-surface distance and a dose rate of $4.0 \mathrm{~Gy} / \mathrm{min}$. $48 \mathrm{~h}$ after transfection of siRNAs cells were harvested for proliferation assay, cell cycle analysis and apoptosis evaluation.

\section{Western blot analysis and kinase assay in vitro}

Cell lysis was performed in RIPA buffer $(50 \mathrm{mM}$ Tris-HCl pH 8.0, $150 \mathrm{mM} \mathrm{NaCl}, 1 \% \mathrm{NP}-40,0.5 \% \mathrm{Na}$-desoxycholate, $0.1 \%$ SDS, $1 \mathrm{mM} \mathrm{Na}_{3} \mathrm{VO}_{4}, 1 \mathrm{mM}$ phenylmethylsulphonyl-fluoride (PMSF), 1 mM Dithiothreitol (DTT), $1 \mathrm{mM} \mathrm{NaF}$, and protease inhibitor cocktail Complete (Roche, Mannheim)). Total protein was separated by using $12 \%$ sodium dodecyl sulfate-polyacrylamide gel electrophoresis (SDS-PAGE) and then transferred to Immobilon-P membranes (Millipore, Bedford, MA). Membranes were exposed to corresponding antibodies for $1 \mathrm{~h}$ in PBS containing 5\% slim milk, washed with phosphate-buffered saline (PBS) containing $0.2 \%$ Tween-20, incubated subsequently with secondary antibodies for $1 \mathrm{~h}$. Finally, the protein bands were visualized with the enhanced chemiluminescence reagent (ECL, Pierce, Rockford). Mouse monoclonal antibodies against cyclin B1 $(1: 5,000)$, Cdk1 (1:2,000), anti-mouse secondary antibodies $(1: 4,000)$ and anti-rabbit secondary antibodies $(1: 4,000)$ were purchased from Santa Cruz (Heidelberg). Rabbit polyclonal antibodies against PARP (poly(ADP-ribose) polymerase, 1: 1000) were from Cell Signaling Technology (Beverly). Mouse monoclonal antibodies against $\beta$-actin $(1: 200,000)$ were obtained from Sigma-Aldrich. Western blots were quantified by applying a Kodak gel documentation system (model 1D 3.5) and standardized with loading control. For kinase assays in vitro, antibodies against cyclin B1 (Santa Cruz, Heidelberg) were used for immunoprecipitation from $600 \mu \mathrm{g}$ of cellular extracts. $0.5 \mu \mathrm{g}$ histone $\mathrm{H} 1$ (Calbiochem, Darmstadt) served as substrate for each reaction. Kinase assays were performed as previously described [29].

\section{Cell proliferation, cell cycle analysis and apoptosis assay}

Cell viability was assessed by trypan blue staining. The proliferation rate of cells was determined at indicated time points by counting cell numbers with a hemacytometer. All experiments were performed in triplicate. For cell cycle analysis, cells were harvested, washed with PBS and fixed in $70 \%$ chilled ethanol at $4{ }^{\circ} \mathrm{C}$ for $30 \mathrm{~min}$, then treated with $1 \mathrm{mg} / \mathrm{ml}$ of RNase A (Sigma-Aldrich) and stained with $100 \mu \mathrm{g} / \mathrm{ml}$ of propidium iodide for $30 \mathrm{~min}$. The DNA content of 10,000 cells was determined with a fluorescent-activated cell sorter FACScan (Becton Dickinson Biosciences, Heidelberg). The data were analysed with cell cycle analysis software ModFit LT 2.0 (Verity Software House, Topsham, ME). Most of the experiments were performed in triplicate. Indirect immunofluorescence staining for subcellular cyclin B1 localization and DNA were carried out as previously described [29]. Apoptosis was assessed using Vybrant ${ }^{\mathrm{TM}}$ apoptosis assay kit according to the manufacturer's instructions (Molecular Probes, Leiden).

\section{Colony formation assay and in vivo experiments}

MCF-7 cells were treated with siRNA1-3 or siGFP for $48 \mathrm{~h}$ and harvested for colony formation assays. Briefly, cells were seeded in 24 well-plates at a density of 200 cells/well into culture medium containing $0.3 \%$ agar (Roth, Karlsruhe) overlaying $0.5 \%$ agar. Cells were cultured at $37^{\circ} \mathrm{C}$ with $5 \% \mathrm{CO}_{2}$, and colonies were counted 4 weeks later using a microscope (Zeiss, Oberkochen). The colony number in control sample was referred as $100 \%$ by quantification.

As to experiments in vivo, HeLa cells were treated with siRNA3 or siGFP and harvested after $48 \mathrm{~h}$. HeLa cells $(1 \times$ $10^{6}$ ) were resuspended in $300 \mu \mathrm{l}$ of $0.9 \% \mathrm{NaCl}$ and subcutaneously injected into both flanks of nude mice. Each group contained 4 mice. Three weeks after inoculation the tumor sizes were measured every 3-4 days using callipers and the tumor volumes were calculated according to a standard formula: $\pi / 6 \times$ length $\times$ width $^{2}$. The tumor volumes within the group were represented by the mean value. All mice were properly treated in accordance with the guidelines of the local animal committee.

\section{Statistic analysis}

For assays in vitro, Student's $t$-tests were used to evaluate the significance of difference between control cells and siRNAs-treated cells. Differences were considered as statistically significant when $p<0.05$. With xenograft mouse model, the significant difference between the siGFPtreated group and siRNA3-treated group was analyzed by Mann-Whitney U test.

\section{Results}

Cancer cell lines lend themselves as useful models to further our understanding of gynecological cancers such as 
breast and cervical cancer. To study the function of cyclin B1 in breast cancer cells we selected cancer cell lines MCF7, BT-474, SK-BR-3 and MDA-MB-231, as they represent the best characterized cell lines for breast cancer research. While MCF-7 and BT-474 express both estrogen receptor (ER) and progesterone receptor (PgR), SK-BR-3 and MDAMB-231 cells lack those receptors [30]. Unlike SK-BR-3 and BT-474, which are Her-2/neu-positive, MCF-7 cells only exhibit a basal level of Her-2/neu [30]. In addition, MCF-7 cells express high amounts of markers typical of the luminal epithelia phenotype of breast cells, whereas BT-474 and SK-BR-3 cells exhibit a weakly luminal epithelia-like phenotype. Distinct from the two phenotypes above, MDA-MB-231 represents a highly invasive "mesenchymal-like" breast cancer cell line by expressing a high level of vimentin. In addition, the cervical cancer cell line HeLa was selected, because it represents the most extensively studied cancer cell line thus far.

\section{Specific downregulation of cyclin BI with siRNA}

We were at first interested whether breast cancer cell lines are similarly sensitive to specific downregulation of cyclin B1 by siRNA. As shown in Fig. 1A, while the protein level of cyclin B1 in MDA-MB-231 was almost undetectable after treatment with siRNA1 or siRNA3, 33\% and $16 \%$ of cyclin B1 were still detectable in MCF-7 cells after treatment with siRNA1 and siRNA3, respectively, relative to the protein level of cyclin B1 in control cells. In contrast to cyclin B1, $\beta$-actin was not affected. The protein level of Cdk1, the catalytic partner of cyclin B1, hardly changed, indicating cyclin B1 knockdown by siRNAs was specific. Treatment of BT-474 and SK-BR-3 cells with siRNA1 and siRNA3 also reduced cyclin B1 levels, albeit to a lower extent as compared to MDA-MB-231 and MCF-7 cells. Downregulation of cyclin B1 was also corroborated by indirect immunofluorenscence staining with monoclonal specific antibodies against cyclin B1 (data not shown). Furthermore, in consistence with downregulation of cyclin $\mathrm{B} 1$ protein, the kinase activity of $\mathrm{Cdk} 1 /$ cyclin $\mathrm{B} 1$ was decreased to $28 \%$ in cellular extracts from siRNA1-treated BT-474 cells as compared to siGFP-treated cells (Fig. 1B). Similar results were also obtained in MCF-7 cells after siRNA administration (data not shown).

\section{Proliferation is inhibited in breast cancer cells with reduced cyclin BI}

As Cdk1/cyclin B1 is essential for the initiation of mitosis and required for cell division we subsequently studied the impact of cyclin B1 downregulation on cell proliferation rate. Expectedly, a reduced proliferation was observed in all four breast cancer cell lines after $48 \mathrm{~h}$ treatment with siRNAs as compared to control cells treated with siGFP (Fig. 2). In particular, MCF-7 cells exhibited a strong inhibition of proliferation, followed by MDA-MB-231, BT474 and SK-BR-3 cells after $48 \mathrm{~h}$ siRNA1-3 treatment against cyclin B1 (Fig. 2A-D, upper panels). Analyses of cell cycle distribution displayed an accumulation of cells in $\mathrm{G} 2 / \mathrm{M}$ phase, suggestive of a G2/M arrest, after treatment with siRNA1-3 targeting cyclin B1 (Fig. 2A-D, lower panels).

\section{Time kinetics of siRNA treatment in MCF-7 cells}

In order to study the effect of cycin B1 knockdown on proliferation, we subjected MCF-7 cells to more detailed time dependent analysis. MCF-7 cells were treated with siRNA1 or siRNA3 and harvested for Western blot analysis and proliferation assay at the indicated time points. The reduction of cyclin B1 protein levels were evident $24 \mathrm{~h}$ after siRNA1/3 treatment as compared to control cells (Fig. $3 \mathrm{~A})$. This effect increased dramatically with time and after $96 \mathrm{~h}$ cyclin $\mathrm{B} 1$ protein became undetectable. In line with the reduction of cyclin B1, the proliferation rate of MCF-7 cells was clearly inhibited at $24 \mathrm{~h}$ with siRNA3 treatment and the inhibition became more striking with longer exposure to siRNA1 (Fig. 3B).

\section{Suppression of cyclin BI renders cells more susceptible to taxol}

Taxol (Paclitaxel ${ }^{\varpi}$ ), a taxane frequently used in multidrug regiments for the therapy of several solid tumors, binds to the $\beta$-subunit of tubulin, thereby impairing the dynamics of microtubules by promoting their polymerization, leading to mitotic arrest and apoptosis [31]. In order to explore cyclin B1 knockdown as a possible combination with taxol, we transfected MCF-7 cells with siRNA3 and followed by further incubation with taxol. Cells were harvested $48 \mathrm{~h}$ posttransfection. As depicted in Fig. 4A, cyclin B1 protein level was strongly reduced after siRNA3 treatment. Cyclin B1 level was also decreased after treatment with taxol at a low dosage of $3 \mathrm{ng} / \mathrm{ml}$, possibly due to the induction of apoptosis, and almost disappeared when cells were pre-treated with siRNA3 (Fig. 4A, upper panel). Indeed, PARP (poly(ADP-ribose) polymerase) was cleaved in cells treated with taxol and more strongly cleaved when siRNA3 was used together with taxol (Fig. $4 \mathrm{~A}$, middle panel), indicating that the combined treatment triggers more robust apoptotic response. In addition, proliferation was inhibited to a higher extent after the combined treatment (Fig. 4B). The results were further correlated with the cell cycle analysis: a G2/M population was more prominent in MCF-7 cells after the combined treatment, compared to cells exposed to siRNA3 alone (Fig. 4C). The data indicate that the combined therapy activates more strongly caspase- 3 independent apoptotic pathways in MCF-7 cells as the caspase- 3 gene is deleted in MCF-7 cells [32]. Similar results were also obtained in MDA-MB-231 cells: while siRNA3 or taxol alone reduced proliferation by $33 \%$ and $31 \%$, respectively, relative to siGFP treatment, the combination of siRNA3 with taxol resulted in a $65 \%$ reduction of proliferation (data not 
A
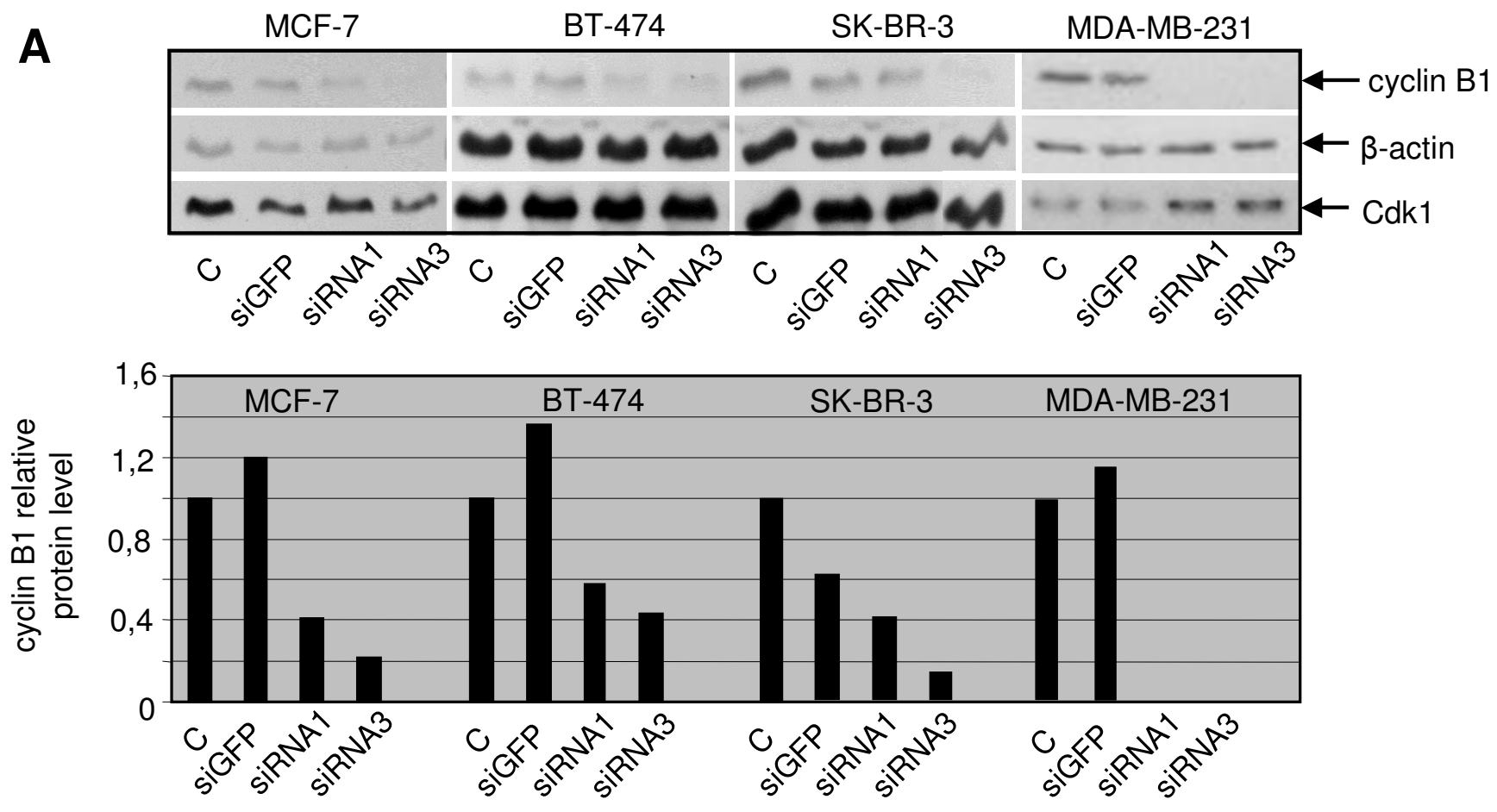

B

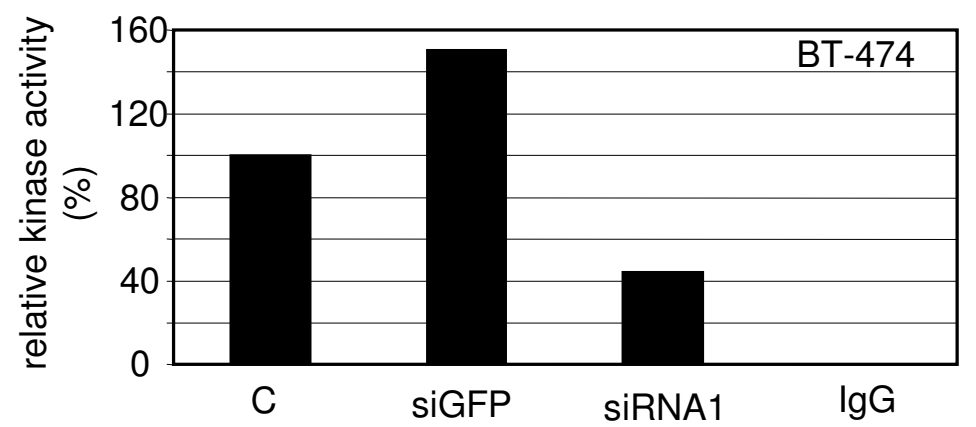

Figure I

Reduced cyclin B I protein and kinase activity of Cdk I/cyclin B I. A. Upper panel: Breast cancer cells MCF-7, BT-474, SK-BR-3 and MDA-MB-23 I cells were treated with cyclin BI siRNAI, siRNA3, GFP siRNA (GFP) or without treatment (C) for 48 h. Cells were harvested and cellular lysates were prepared for Western blot analyses with antibodies targeting cylin BI, CdkI and $\beta$-actin. The later served as loading control. Lower panel: Quantification of cyclin BI levels from Western blots (upper panel), normalized to $\beta$-actin. B. Kinase assay of CdkI/cyclin BI in vitro. BT-474 cells were treated with cyclin BI siRNAI or siGFP or without treatment (C). $24 \mathrm{~h}$ later cells were lysed and Cdk I/cyclin BI complex was immunoprecipitated by using antibodies against cyclin BI from cellular extracts. Normal lgG served as negative control. Kinase assays were carried out with the precipitates in the presence of histone $\mathrm{HI}$ as substrate.

shown). Thus, the combined action of cyclin B1 knockdown together with taxol enhances antiproliferative and proapoptotic responses in breast cancer cells. Furthermore, we investigated the combination of knockdown of cyclin B1 with irradiation. Irradiation enhanced the G2/M population and induced more apoptosis in cyclin B1 reduced MCF-7 cells, compared to control cells (data not shown).

\section{Impaired colony-forming ability and inhibited tumor growth}

Anchorage independent cell growth is one of the hallmarks of malignant tumor cells. Given the notion of cyclin B1 deregulation being involved in neoplastic transformation and associated with malignancy grade of tumors, we wondered whether knockdown of cyclin B1 protein might translate into reduced colony-forming abil- 
A
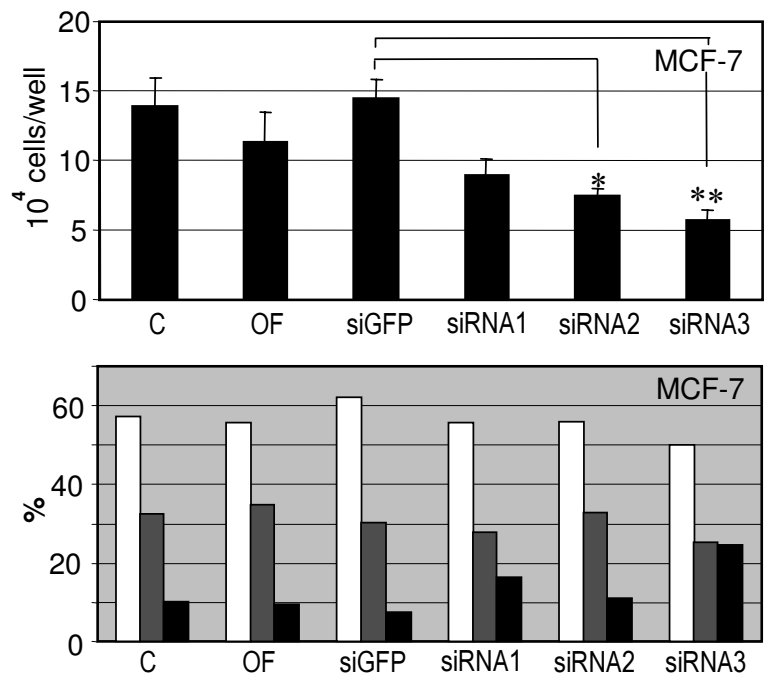

C
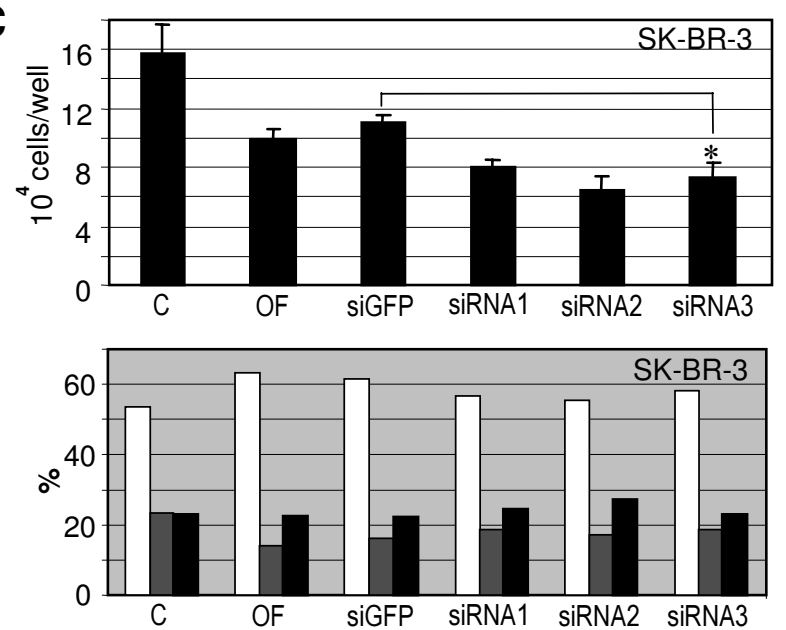

B
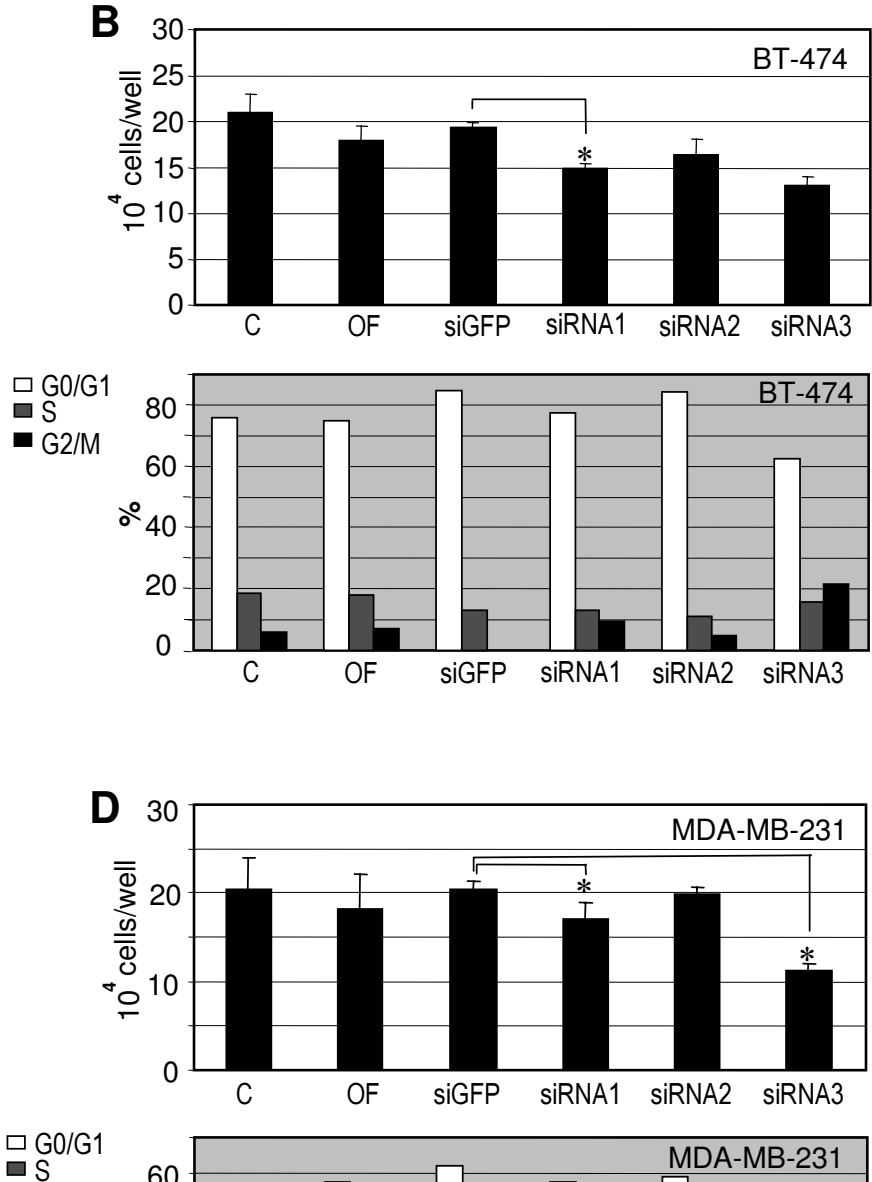

$\square \mathrm{S} 2 / \mathrm{M}$

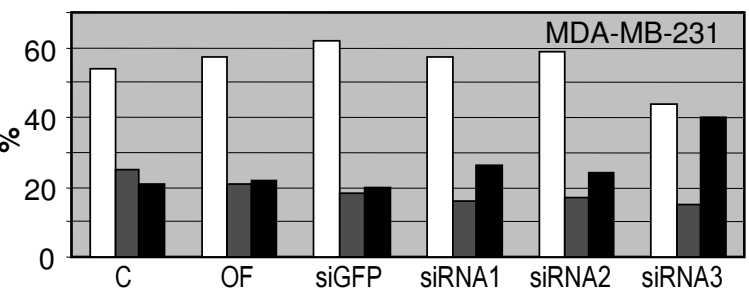

Figure 2

Inhibited proliferation after downregulation of cyclin B I. MCF-7 (A), BT-474 (B), SK-BR-3 (C) and MDA-MB-23 I cells (D) were treated with siRNAI-3, or siGFP or oligofectamine alone (OF). After $48 \mathrm{~h}$ cells were harvested for cell number counting (upper panels in Fig. 3 A-D) and for cell cycle analysis (lower panels in Fig. 3 A-D). Cells without any treatment (C) served as control. The results of cell numbers are expressed as mean \pm SD $(n=3)$ and statistically analysed. $* P<0.05$, $* * P<$ 0.01 .

ity in MCF-7 cells. As shown in Fig. 5A, the colony numbers of MCF-7 cells treated with siRNA1-3 were strongly reduced, in particular, in MCF-7 cells treated with siRNA3, compared to controls.

Cervical carcinoma HeLa cells express a high level of cyclin B1 (data not shown). In cell culture, only 25-30\% HeLa cells were left after 48 h treatment with siRNA3 targeting cyclin B1 (data not shown). To further address whether cyclin $\mathrm{B} 1$ is required for aggressive growth of tumors in vivo, a xenograft experiment with HeLa cells was performed in nude mice. Mice were inoculated with HeLa cells treated $48 \mathrm{~h}$ with siRNA3 targeting cyclin B1 or siGFP. As shown in Fig. 5B, tumor growth of HeLa cells treated with siRNA3 prior to inoculation was effectually retarded, in comparison with the growth of control HeLa tumors. The data suggest that cyclin B1 is indeed required in vivo for promoting proliferation of tumor cells and the reduction of cyclin $\mathrm{B} 1$ slows down the tumor growth. 


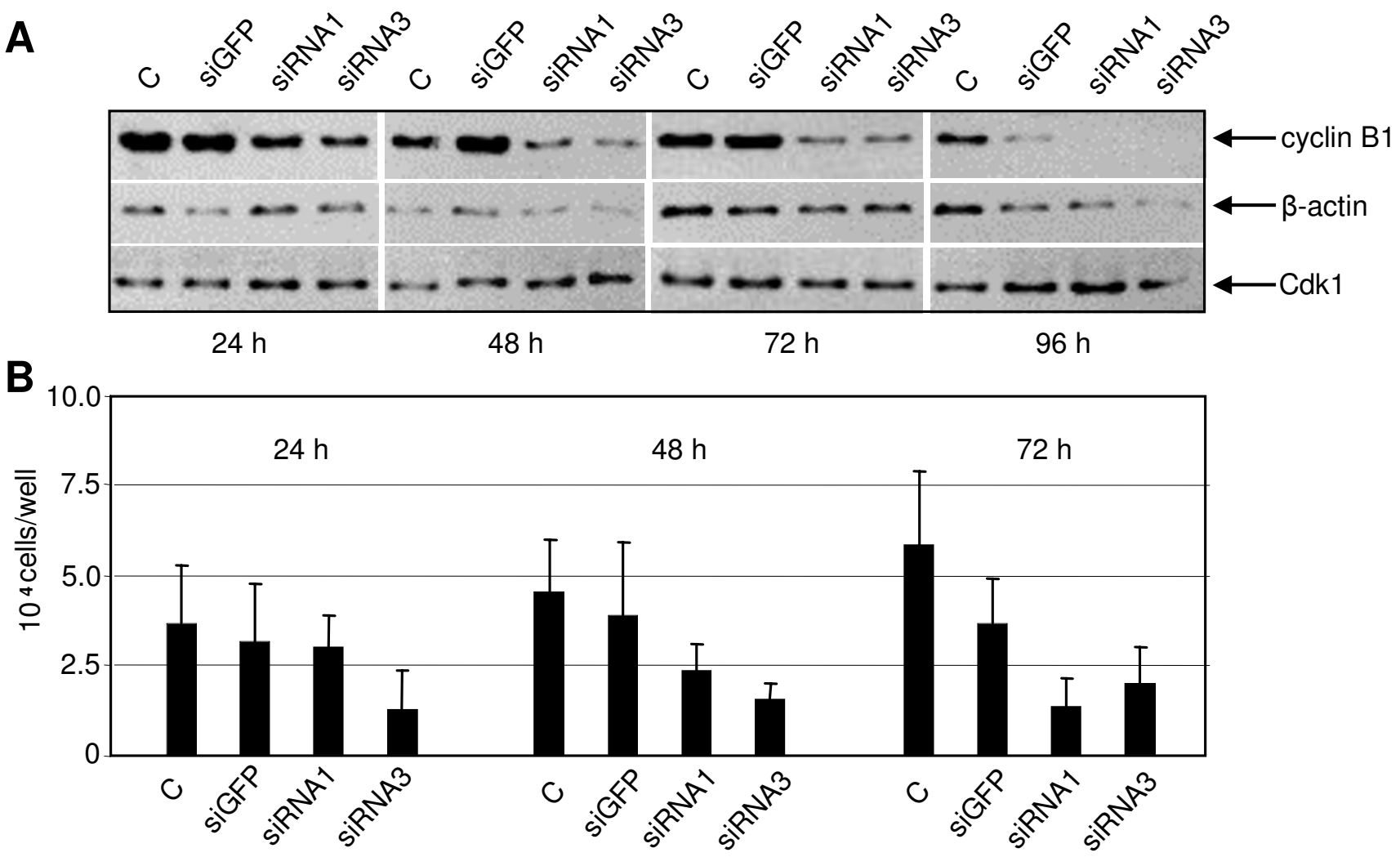

Figure 3

Time kinetics in MCF-7 cells. MCF-7 cells were treated with cyclin BI siRNAI, siRNA3, siGFP or without treatment (C). Treated cells were harvested at different time points as indicated for Western blot analyses with antibodies against cyclin BI, $\mathrm{CdkI}$ and $\beta$-actin (A) and for cell number determinations (B). The results of cell numbers are expressed as mean \pm SD $(n=3)$.

\section{Discussion}

The prognosis of breast and cervical cancer patients has been improved during recent years, related partly to sophisticated surgery, radiotherapy and adjuvant systemic therapy. Despite these advances, these cancers remain major clinical problems by causing considerable morbidity and mortality in women worldwide. Apart from the standard approaches, novel potent molecular agents for anticancer therapy are in great demand.

In this communication we show that the knockdown of cyclin B1, the regulatory subunit of Cdk1, inhibited cell proliferation and induced apoptosis in various breast and cervical cancer cell lines. Importantly, siRNA mediated cyclin B1 knockdown in combination with chemotherapeutical agent taxol, enhanced the antiproliferative effect on breast cancer cells. Interestingly, the reduction of cyclin B1 in MCF-7 cells impaired colony-forming ability, a hallmark of malignancy in tumor cells. Moreover, while control HeLa cells were progressively growing, the tumor growth of HeLa cells treated with siRNA targeting cyclin B1 prior to inoculation was strongly inhibited in nude mice, indicating cyclin B1 is indispensable for tumor growth in vivo. Taken together, the data strengthen the notion of cyclin B1 being required for the survival and proliferation of breast and cervical cancer cells and depletion/downregulation of cyclin B1 inhibits proliferation of cancer cells in vitro as well as in vivo.

Recent genetic evidence demonstrates that Cdk1 is the only Cdk sufficient to drive the mammalian cell cycle because embryos from Cdk $1 \%$ - mice fail to develop to the morula and blastocyst stages, whereas mouse embryos lacking all interphase Cdks (Cdk2, Cdk3, Cdk4 and Cdk6) undergo organogenesis and develop to midgestation [33]. These data underscore that Cdk1 is essential for cell cycle regulation and a major force driving cell proliferation. Cyclin $\mathrm{B} 1$, the regulatory subunit of $\mathrm{Cdk} 1$, controls the activity of Cdk1 as it associates with and thereby activates Cdk1, regulates its nuclear translocation and passively mediates its inactivation when cyclin B1 is degraded at anaphase transition. Cyclin B1 is fundamental for cell proliferation. Uncontrolled expression of cyclin B1 is associated with neoplastic transformation and gynecological cancer development $[5,9,11,34,35]$. Overexpression of cyclin B1 is believed to confer therapy resistance $[8,11]$. 
A

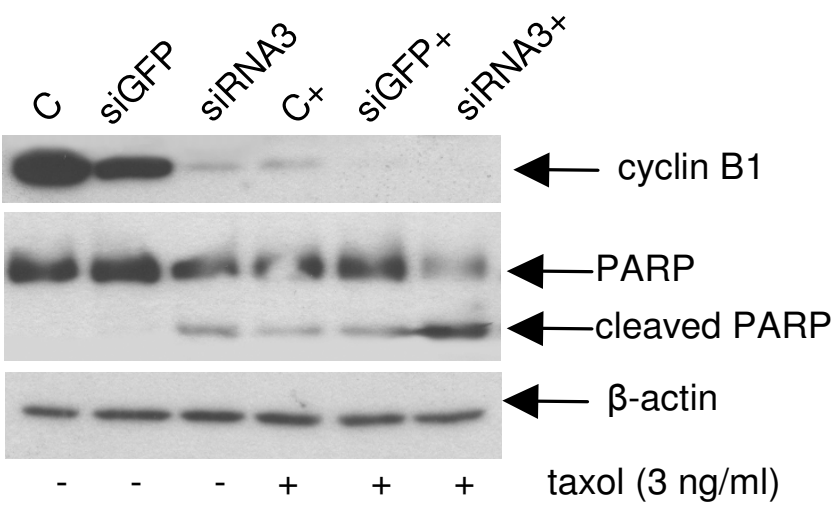

B

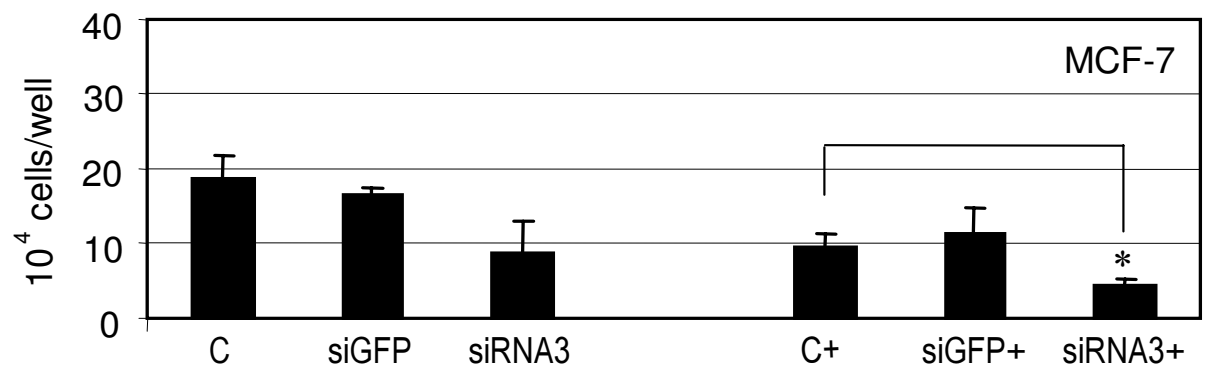

C
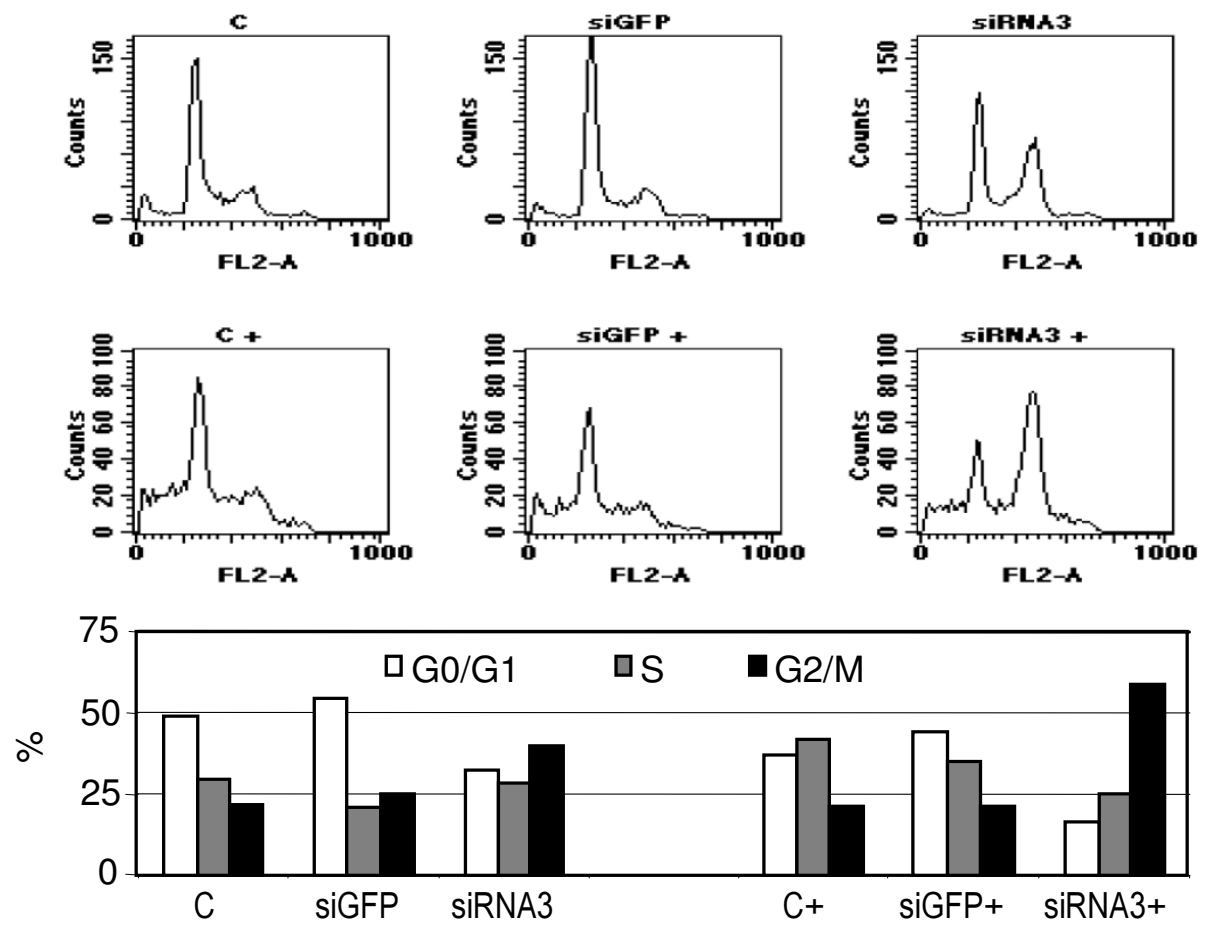

Figure 4

More sensitive to taxol in MCF-7 cells with reduced cyclin B I. A. MCF-7 cells were transfected with siRNA3 or siGFP and $4 \mathrm{~h}$ later followed with treatment of taxol ( $\mathrm{C}+$, siGFP+ and siRNA3+) or without taxol (C, siGFP and siRNA3). $48 \mathrm{~h}$ after transfection cells were harvested for Western blot analyses with antibodies as indicated. $\beta$-actin served as loading control. PARP: poly (ADP-ribose) polymerase. B. Cells were treated as in $A$ and cell numbers were counted. The results are expressed as mean $\pm S D(n=3)$ and statistically analysed. $* P<0.05$. C. MCF-7 cells were treated as in $A$ and cell cycle was analyzed (upper panel) and distribution of cell cycle population was quantified (lower panel). 
A

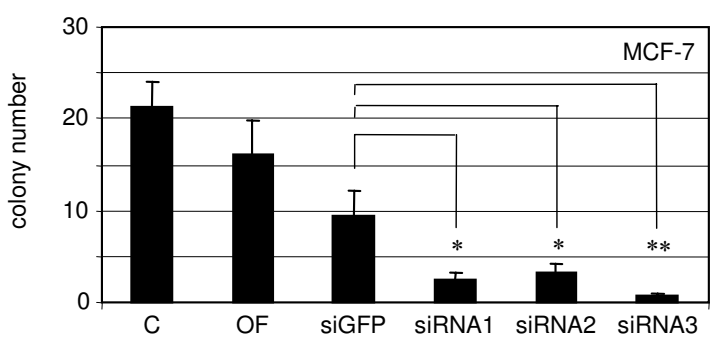

B

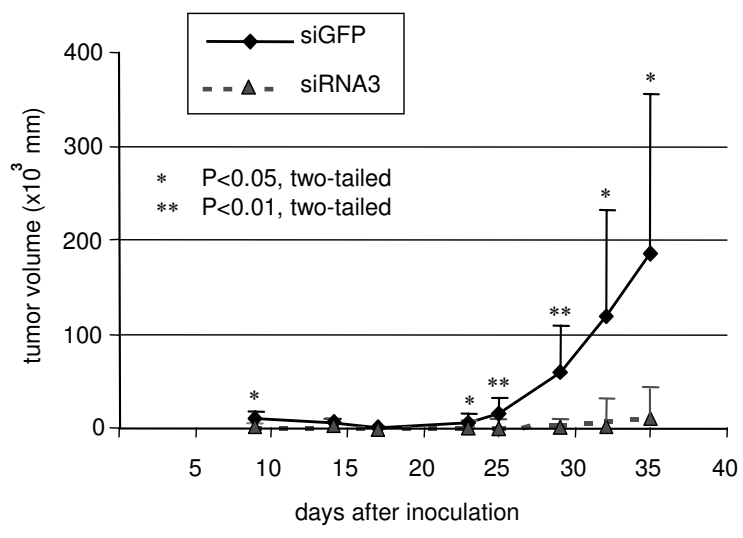

Figure 5

Impaired colony-forming ability and reduced tumor growth. A. Colony formation assay. MCF-7 cells were treated with siRNAI -3 or siGFP. $48 \mathrm{~h}$ after transfection cells were transferred to soft-agar plates for further incubation. 4 weeks later the colony numbers were scored with a microscope. The colony number of control cells was regarded as $100 \%$ for calculation. The data were expressed as mean \pm SD $(n=3)$ and analysed by Student's $t$-test. $* P<0.05, * * P<0.01$. B. Xenograft experiment in nude mice. I $\times 10^{6}$ of HeLa cells treated with siRNA3 or control siGFP were subcutaneously injected into each flank of nude mice. Each group contained 4 mice. Tumor sizes were measured every 2-3 days and tumor volumes were calculated. The data were statistically analysed by Mann-Whitney $U$ test. $* P<0.05$, ${ }^{* *} P<0.01$.

Thus, targeting cyclin B1, leading consequently to the inactivation of Cdk1, could be a promising specific strategy for cell cycle intervention against breast and cervical cancer.

In this work, as a proof-of-concept, the RNA interference was used to downregulate/deplete cyclin B1 and a clear antiproliferative effect was observed in all cancer cell lines studied. Among the breast cancer cell lines investigated, MCF-7 cells exhibited the strongest inhibitory effect on cell proliferation after cyclin B1 siRNA treatment, followed by MDA-MB-231, SK-BR-3 and BT-474 cells (Fig. 2), which possibly correlates with the cyclin B1 level in exponential growing status of each cell line (data not shown). Although the protein level of cyclin B1 in MDAMB-231 cells was nearly undetectable after siRNA1 or
siRNA3 transfection, the inhibitory impact was moderate (Fig. 2D), suggesting the proliferation of MDA-MB-231 cells is not necessarily dependent on the normal level of cyclin B1 and the little amount of remaining cyclin B1 might be sufficient for the survival of MDA-MB-231 cells. Finally, SK-BR-3 and BT-474 cells were also not as sensitive to siRNA treatment (Fig. 2B and 2C) as HeLa or MCF7 cells. This could be due to the cellular context of SK-BR3 and BT-474 cells, e.g. Her-2/neu+, which very often leads to a hormone-independent proliferation of cells. Thus, unlike in MCF-7 cells, targeting Her-2/neu or other factors promoting G1/S transition could be more effective for inhibiting cell cycle progression in SK-BR-3 and BT-474 cells, which has been shown by our previous study [36]. On that account, specific targeting of oncogene(s) in individual cancer cell lines, like Her-2/neu in SK-BR-3 and BT474 cells, or cyclin B1 in MCF-7, could improve breast cancer therapy. Collectively, downregulation/depletion of cyclin B1 worked effectively in all gynecological cancer cell lines tested. However, only in some cell lines, such as MCF-7 and HeLa, cyclin B1 knockdown resulted in a strong proliferative inhibition, most likely because proliferation in those cell lines is more dependent on high cyclin B1 levels as compared to other cell lines.

Taxane drugs represent the most important class of anticancer agents and are integrated in multidrug-regiments for the therapy of several solid tumors including gynecological cancers. Despite their relevant contribution in ameliorating the quality of life and overall survival of cancer patients, drug resistance and site-effects hamper its wide usage. Therefore, it is desirable to find new ways of lowering drug dosage without losing effectiveness to limit side-effects and possibly also to slow down drug resistance. In this work, cyclin B1 siRNA in combination with taxol, blocking entry into mitosis and targeting the transition of metaphase to anaphase, respectively, demonstrated a high efficacy in inhibiting proliferation of MCF7 cells. The data suggest that specific targeting of cyclin B1 could sensitize some gynecological cancer cells, like MCF7 and MDA-MB-231 cells, to conventional chemotherapeutic agents like taxol, thereby reducing their side-effects by lowering their dosage.

Taken together, the data from this work further strengthen the notion that cyclin $\mathrm{B} 1$ could be an attractive target for potential anticancer therapy. Inhibiting cyclin B1 function in combination with chemotherapeutic drugs could reinforce the antiproliferative effect in a subset of cancers. As RNA interference still faces the major challenge of systematic delivery [37], an alternative strategy could be small molecule inhibitors targeting cyclin B, as its crystal structure is recently published [38]. In parallel to Cdk inhibitors, which have been extensively under clinical investigations, small molecule inhibitors against cyclin B1 
could open up a new door for specific molecular cancer therapy by interfering with its protein stability, binding capacity to Cdk1 or its subcellular localization.

\section{Conclusion}

This work demonstrates that cyclin B1 is required for survival and proliferation of breast and cervical cancer cells. Downregulation of cyclin B1 inhibits proliferation of tumor cells in vitro as well as in vivo and sensitizes breast cancer cells to taxol. The data indicate that the combination of reducing cyclin B1 with chemotherapeutic drugs could be a new strategy for molecular intervention in a subset of breast cancers.

\section{Competing interests}

The authors declare that they have no competing interests.

\section{Authors' contributions}

IA and AK conducted cell cycle analyses, proliferation assays, Western blot analyses, apoptosis assays and mouse xenograft experiments in vivo. RY performed the kinetics of MCF-7 cells and soft-agar assays. FR is involved in the combination therapy and assays. MK and RG coordinated this project. KS co-supervised this study and supported the manuscript writing. JY designed and supervised this study, and drafted the manuscript. All the authors read and approved the final manuscript.

\section{Acknowledgements}

This work was supported by the Deutsche Krebshilfe (\#107594). We gratefully acknowledge the help of Dr. F. Eckerdt (Howard Hughes Medical Institute and Department of Pharmacology, University of Colorado, School of Medicine), who improved and modified the manuscript. We thank also Dr. S. Kappel for critical reading the manuscript. We are grateful to Ms $\mathrm{H}$. Beschmann and Ms S. Diehl, Department of Dermatology, University of Frankfurt, for supporting apoptotic analysis.

\section{References}

I. Weigelt B, Peterse JL, 't Veer LJ: Breast cancer metastasis: markers and models. Nat Rev Cancer 2005, 5:591-602.

2. Schiffman M, Castle PE, Jeronimo J, Rodriguez AC, Wacholder S: Human papillomavirus and cervical cancer. Lancet 2007, 370:890-907.

3. Wang A, Yoshimi N, Ino N, Tanaka T, Mori H: Overexpression of cyclin BI in human colorectal cancers. J Cancer Res Clin Oncol 1997, I 23:124-127.

4. Zhao M, Kim YT, Yoon BS, Kim SW, Kang MH, Kim SH, Kim JH, Kim JW, Park YW: Expression profiling of cyclin BI and DI in cervical carcinoma. Exp Oncol 2006, 28:44-48.

5. Kawamoto H, Koizumi H, Uchikoshi T: Expression of the G2-M checkpoint regulators cyclin $B I$ and cdc2 in nonmalignant and malignant human breast lesions: immunocytochemical and quantitative image analyses. Am J Pathol 1997, I 50:I5-23.

6. Soria JC, Jang SJ, Khuri FR, Hassan K, Liu D, Hong WK, Mao L: Overexpression of cyclin $B I$ in early-stage non-small cell lung cancer and its clinical implication. Cancer Res 2000, 60:4000-4004.

7. Banerjee SK, Weston AP, Zoubine MN, Campbell DR, Cherian R: Expression of cdc2 and cyclin BI in Helicobacter pylori-associated gastric MALT and MALT lymphoma: relationship to cell death, proliferation, and transformation. Am J Pathol 2000, I 56:217-225.

8. Hassan KA, Ang KK, El Naggar AK, Story MD, Lee JI, Liu D, Hong WK, Mao L: Cyclin B I overexpression and resistance to radi- otherapy in head and neck squamous cell carcinoma. Cancer Res 2002, 62:6414-6417.

9. Rudolph P, Kuhling H, Alm P, Ferno M, Baldetorp B, Olsson H, Parwaresch R: Differential prognostic impact of the cyclins $E$ and $B$ in premenopausal and postmenopausal women with lymph node-negative breast cancer. Int J Cancer 2003, 105:674-680.

10. Nozoe T, Korenaga D, Kabashima A, Ohga T, Saeki H, Sugimachi K: Significance of cyclin B I expression as an independent prognostic indicator of patients with squamous cell carcinoma of the esophagus. Clin Cancer Res 2002, 8:817-822.

II. Suzuki T, Urano T, Miki Y, Moriya T, Akahira J, Ishida T, Horie K, Inoue S, Sasano H: Nuclear cyclin BI in human breast carcinoma as a potent prognostic factor. Cancer Sci 2007, 98:644-65I.

12. Egloff AM, Vella LA, Finn OJ: Cyclin BI and other cyclins as tumor antigens in immunosurveillance and immunotherapy of cancer. Cancer Res 2006, 66:6-9.

13. Suzuki H, Graziano DF, McKolanis J, Finn OJ: T cell-dependent antibody responses against aberrantly expressed cyclin B I protein in patients with cancer and premalignant disease. Clin Cancer Res 2005, I I: I52 I- I 526.

14. Innocente SA, Abrahamson JL, Cogswell JP, Lee JM: p53 regulates a G2 checkpoint through cyclin B I. Proc Natl Acad Sci USA 1999, 96:2147-2I 52.

15. Passalaris TM, Benanti JA, Gewin L, Kiyono T, Galloway DA: The G(2) checkpoint is maintained by redundant pathways. Mol Cell Biol 1999, 19:5872-588I.

16. Taylor WR, DePrimo SE, Agarwal A, Agarwal ML, Schonthal AH, Katula KS, Stark GR: Mechanisms of $\mathbf{G 2}$ arrest in response to overexpression of p53. Mol Biol Cell 1999, 10:3607-3622.

17. MacLachlan TK, Dash BC, Dicker DT, El Deiry WS: Repression of BRCAI through a feedback loop involving p53. J Biol Chem 2000, 275:31869-31875.

18. Yin XY, Grove L, Datta NS, Katula K, Long MW, Prochownik EV: Inverse regulation of cyclin $B I$ by c-Myc and p53 and induction of tetraploidy by cyclin BI overexpression. Cancer Res 2001, 6 I:6487-6493.

19. Zoubine MN, Weston AP, Johnson DC, Campbell DR, Banerjee SK: 2-methoxyestradiol-induced growth suppression and lethality in estrogen-responsive MCF-7 cells may be mediated by down regulation of $\mathrm{p} 34 \mathrm{cdc} 2$ and cyclin $B I$ expression. Int J Oncol 1999, I 5:639-646.

20. Perks CM, Gill ZP, Newcomb PV, Holly JM: Activation of integrin and ceramide signalling pathways can inhibit the mitogenic effect of insulin-like growth factor I (IGF-I) in human breast cancer cell lines. Br J Cancer 1999, 79:701-706.

21. Schroeder MD, Symowicz J, Schuler LA: PRL modulates cell cycle regulators in mammary tumor epithelial cells. Mol Endocrinol 2002, 16:45-57.

22. Cho NH, Kang S, Hong S, An HJ, Choi YH, Jeong GB, Choi HK: Elevation of cyclin B I, active cdc2, and HuR in cervical neoplasia with human papillomavirus type 18 infection. Cancer Lett 2006, 232: $170-178$.

23. Shen M, Feng Y, Gao C, Tao D, Hu J, Reed E, Li QQ, Gong J: Detection of cyclin bl expression in $g(I)$-phase cancer cell lines and cancer tissues by postsorting Western blot analysis. Cancer Res 2004, 64:1607-1610.

24. Collecchi P, Santoni T, Gnesi E, Giuseppe NA, Passoni A, Rocchetta M, Danesi R, Bevilacqua G: Cyclins of phases G I, S and G2/M are overexpressed in aneuploid mammary carcinomas. Cytometry 2000, 42:254-260.

25. Jin P, Hardy S, Morgan DO: Nuclear localization of cyclin B I controls mitotic entry after DNA damage. J Cell Biol 1998, | 4 | :875-885.

26. Park M, Chae HD, Yun J, Jung M, Kim YS, Kim SH, Han MH, Shin DY: Constitutive activation of cyclin BI-associated cdc2 kinase overrides p53-mediated G2-M arrest. Cancer Res 2000, 60:542-545.

27. Yuan J, Yan R, Kramer A, Eckerdt F, Roller M, Kaufmann M, Strebhardt K: Cyclin B I depletion inhibits proliferation and induces apoptosis in human tumor cells. Oncogene 2004, 23:5843-5852.

28. Yuan J, Kramer A, Matthess Y, Yan R, Spankuch B, Gatje R, Knecht R, Kaufmann M, Strebhardt K: Stable gene silencing of cyclin B I in tumor cells increases susceptibility to taxol and leads to growth arrest in vivo. Oncogene 2006, 25:1753-1762. 
29. Yuan J, Eckerdt F, Bereiter-Hahn J, Kurunci-Csacsko E, Kaufmann M, Strebhardt K: Cooperative phosphorylation including the activity of polo-like kinase I regulates the subcellular localization of cyclin B I. Oncogene 2002, 2 I:8282-8292.

30. Lacroix M, Leclercq G: Relevance of breast cancer cell lines as models for breast tumours: an update. Breast Cancer Res Treat 2004, 83:249-289.

31. Hernandez-Vargas H, Palacios J, Moreno-Bueno G: Telling cells how to die: docetaxel therapy in cancer cell lines. Cell Cycle 2007, 6:780-783.

32. Simstein R, Burow M, Parker A, Weldon C, Beckman B: Apoptosis, chemoresistance, and breast cancer: insights from the MCF7 cell model system. Exp Biol Med (Maywood) 2003, 228:995- 1003.

33. Santamaria D, Barriere $C$, Cerqueira A, Hunt S, Tardy $C$, Newton $K$, Caceres JF, Dubus $P$, Malumbres M, Barbacid M: Cdk I is sufficient to drive the mammalian cell cycle. Nature 2007, 448:8II-8I5.

34. Zhao M, Kim YT, Yoon BS, Kim SW, Kang MH, Kim SH, Kim JH, Kim JW, Park YW: Expression profiling of cyclin BI and DI in cervical carcinoma. Exp Oncol 2006, 28:44-48.

35. Cho NH, Kang S, Hong S, An HJ, Choi YH, Jeong GB, Choi HK: Elevation of cyclin B I, active cdc2, and $H u R$ in cervical neoplasia with human papillomavirus type 18 infection. Cancer Lett 2006, 232: $170-178$.

36. Faltus T, Yuan J, Zimmer B, Kramer A, Loibl S, Kaufmann M, Strebhardt K: Silencing of the HER2/neu gene by siRNA inhibits proliferation and induces apoptosis in HER2/neu-overexpressing breast cancer cells. Neoplasia 2004, 6:786-795.

37. Bumcrot D, Manoharan M, Koteliansky V, Sah DW: RNAi therapeutics: a potential new class of pharmaceutical drugs. Nat Chem Biol 2006, 2:7II-7I9.

38. Petri ET, Errico A, Escobedo L, Hunt T, Basavappa R: The crystal structure of human cyclin B. Cell Cycle 2007, 6:1342-1349.

\section{Pre-publication history}

The pre-publication history for this paper can be accessed here:

http://www.biomedcentral.com/1471-2407/8/391/pre

pub

Publish with Bio Med Central and every scientist can read your work free of charge

"BioMed Central will be the most significant development for disseminating the results of biomedical research in our lifetime. "

Sir Paul Nurse, Cancer Research UK

Your research papers will be:

- available free of charge to the entire biomedical community

- peer reviewed and published immediately upon acceptance

- cited in PubMed and archived on PubMed Central

- yours - you keep the copyright

Submit your manuscript here:

http://www.biomedcentral.com/info/publishing_adv.asp
BioMedcentral 